\title{
CONGENITAL ECTROPION OF THE UPPER LIDS
}

\author{
BY \\ ROBERT J. YOUNG \\ From the Department of Child Health, Queen's University, Belfast, and the Belfast City Hospital
}

(RECEIVED FOR PUBLICATION OCTOBER 30, 1953)

This report of a case of congenital ectropion is presented not only because of its intrinsic interest and great rarity but also because, so far as one has been able to determine, it is the first case in which an attempt has been made to elucidate the aetiology of the condition by a detailed examination of the lids.

Collins (1915) reported a case of a girl aged 4 months who had bilateral partial ptosis, well marked epicanthus and ectropion of the lower lids. The defect in the eyelids was stated to have been present from birth. The lower lacrymal puncta on each side were present but they stood away from the eyeballs. She was able to use the orbicularis muscles to close her eyes and to screw up her lids. In that case 'a wedge-shaped piece of the whole thickness of the right lower lid was cut out a little way internal to the outer canthus. The base of the wedge was at the free margin of the lid and measured about six millimetres in length. A stitch was inserted through the two raw surfaces left, just inside the line of the lashes, and by means of it they were drawn together and united'. The length of the lower lid was thus shortened and drawn up into a better position. Microscopical examination of sections of the lower lid showed a well-developed orbicularis muscle.

Mackay (1915) described a similar case but with the distinction that in addition to bilateral eversion of the lower lids there was microphthalmos in both eyes and symmetrical coloboma iridum and a deepseated cyst below the left lower lid.

Von Herrenschwand (1916) reported a case of a man aged 48 years who had bilateral ectropion of the upper and lower eyelids since birth. In that case, even without the patient's history that the condition had been present since birth, attention would have been drawn to a congenital anomaly by the absence of the puncta lacrimalia, and by the presence in each eye of a symmetrically situated conjunctival fold which originated from the fundus of the conjunctival sac, and which was inserted in a pinguecular-like thickening encroaching slightly on to the outer limbus of the cornea just below a horizontal meridian.

Gordon and Cragg (1944) reported a case of mild congenital ectropion of all four lids, associated with ptosis of the upper lids. Their patient was a man aged 23 years. He had six brothers and three sisters, of whom two brothers and one sister had a similar but less marked defect. The father of that family was stated to have had a defect of the same nature.

Photographs of the four cases mentioned above show that they do not bear a close resemblance to the picture presented by our case and an exhaustive search of the world literature has revealed only two cases similar to the case reported here.

Erb (1909) described a case of bilateral congenital ectropion of the upper eyelids in a 2-day-old infant. The father said the changes were seen immediately after birth and that they had increased since birth.

Mertens (1920) also reported a case in which there was complete eversion of both upper lids immediately after birth. The mother, a healthy woman aged 42 years, was a seventh para with a generally contracted flat pelvis. All previous births had been difficult, and in all, labour had been prolonged. The ectropion was treated with boric acid and vaseline dressings and eventually completely disappeared but 'there persisted a narrowing of the palpebral fissure especially in the inner canthus and the palpebral fissures were oblique from upper outer towards lower inner angles'. This description, and the photograph of the child, strongly suggest that the case was a mongol, though this possibility was not put forward by Mertens. The child died with convulsions at the age of 4 months.

\section{Case Report}

The patient, a boy weighing $7 \mathrm{lb} .12 \mathrm{oz}$. at birth, was the seventh child of a mother aged 35 years. Previous pregnancies had resulted in the birth at full term of infants whose birth weights ranged from $8 \mathrm{lb}$. to $12 \mathrm{lb}$. At no birth had labour been difficult and all the other children were normal except the sixth, who was a stillborn foetus with hydrocephalus and a cervical meningocoele. 
In the present pregnancy the mother's health was good until the seventh month when she developed signs of mild pre-eclamptic toxaemia. Labour, which lasted six hours, had not been difficult and the child was born, vertex presenting, without the aid of forceps.

Immediately the head appeared at birth both upper lids were seen to be completely everted, and the whole inner surface of the upper lids and a large part of each upper transitional fold lay exposed. The transitional folds were so swollen that the lid opening was completely obliterated. The ectropion appeared as large oedematous swellings covered by a blue-red mucosa. When the child cried the swellings increased in size and the colour became slightly more bluish. The lower lids appeared normal and the eyes, which were seen only with great difficulty on retraction of the lower lids, appeared smaller than normal.

The infant (Fig. 1) had the characteristic stigmata of

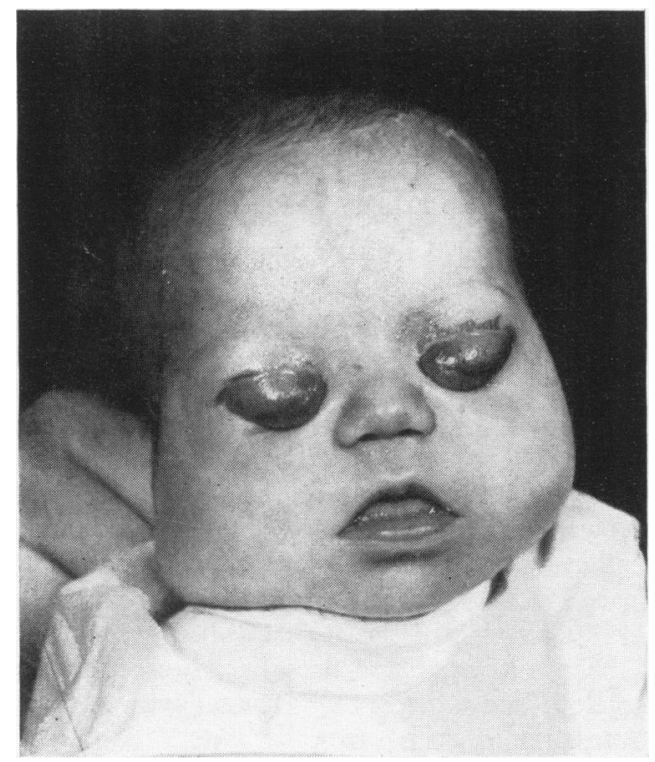

Fig.1.-Large oedematous swelling on each upper lid.

mongolism. The epicanthic fold of skin at the inner canthus was strongly developed and the nose was stubbed. The cranium was devoid of eminences and the occiput flattened. The conjunctival swellings of the upper lids obscured the obliquity of the palpebral fissures but on close inspection it was seen that each outer angle pointed upwards. The tongue was frequently protruded. The palms and soles showed the markings considered to indicate mongolism.

There was no evidence of any birth trauma.

The skin was normal.

A few days after birth the conjunctival swellings became less intense but the ectropion persisted and there was minimal sloughing of the central area of the oedematous swelling on each eye.
On the eighth day of life, under general anaesthesia, the excess tissue beneath the right upper eyelid was excised and the two raw conjunctival margins united by a continuous suture.

The day following the operation the infant had an attack of cyanosis and died suddenly.

Necropsy Report. There was no obvious infection of the operation site. The foramen ovale was widely patent and the mitral valve showed a few little nodular thickenings of the free margin but there was no developmental anomaly of the heart.

The right lung was swollen and felt heavy. The pleura was dark red and dotted with small haemorrhages. On section the consistency was fairly firm especially in the lower lobe. The left lung contained more air and was only moderately congested.

The right kidney showed foetal lobulation. There was a dark red area at the lower pole involving about onethird of the surface and on section there was a haemorrhagic infarct extending to the pelvis. The affected cortex was pale in its inner third. No frank thrombi were seen in the vessels at the hilum.

The left kidney appeared normal.

The brain was congested and very soft. There was no thrombosis of the sinuses and no evidence of meningitis. The body cavities were normal. The liver, spleen, adrenals, bladder, prostate, testicles, oesophagus, small and large intestine, pancreas, thymus, trachea and pituitary were all normal.

Histology. The lungs were extremely congested and there were multiple large intra-alveolar haemorrhages. On the margins of the haemorrhages the alveoli contained oedema fluid and a few large mononuclears but there was no acute inflammatory reaction.

In the kidneys the haemorrhagic area was seen to be a recent infarct. The capsular tissues were oedematous and congested and a narrow subcapsular zone of tissue had survived. The cortex deep to this showed necrosis with nuclear disintegration and a mild inflammatory reaction. The lesion extended partly to the medulla. The blood vessels were congested but no emboli were seen in the arteries, nor thrombi in the veins. The other kidney was much congested but not necrotic.

The liver showed marked congestion and fairly diffuse fatty vacuolation of the liver cells. The portal tracts were normal.

The eyes, on sectioning, showed normal structure and position of the various intra-ocular tissues.

Other organs were normal histologically.

Detailed Report on the Eyelids. After removal of the eyeballs the eyelids were excised by a circular cut around the orbital margins so as to include the full thickness of the lids and as much of the conjunctival tissues as remained in the orbit. The earlier removal of the eyeballs had deranged the lid margins somewhat and the lids were fragmented during preparation. It was thus impossible to estimate precisely the relative amounts of collagenous tissue forming the upper tarsal plates. The lower lids were in a good state of preservation apart from the loss 
of continuity with the inferior rectus and of the reflection of the conjunctiva on to the eyeball.

Comparison was made with sagittal midline sections of the lids and eyeballs of a 35-week male foetus. In so far as the material allowed of comparison, the absolute and relative thicknesses of the various components of the lids were measured at a distance of $2 \mathrm{~mm}$. from the free margins of the lids, and the absolute as well as the relative values of the components compared.

There was no appreciable difference in the absolute thickness of the subconjunctival collagen layer, of the thickness of the meibomian glands, of the ratio of thickness of collagen to that of gland or of thickness of orbicularis palpebrarum muscle to thickness of lid, between the control and the lower lids of the specimen. It was not possible to measure these constituents of the upper lids of the specimen but a firm impression was formed that the amounts of muscle, gland and collagen were comparable to the control.

Right UPPER LID (Operated Side). The lid margin was torn and the meibomian glands almost gone. There was a well marked notch on the inner aspect of the lid at the site of operative removal of tissue, only skin and subcutaneous collagen remaining.

I.EFT UPPER LID (Non-Operated Side). The lid margin was torn and the continuity of skin and conjunctiva was lost. The meibomian glands were well developed and embedded in collagen tissue of approximately normal amount. The orbicularis muscle was well developed but the insertion of the levator palpebrae superioris and superior rectus tendons into the lid could not be compared with the normal owing to prior removal of the eyeball.

Right Lower LiD (Operated Side). Well developed meibomian glands were embedded in collagen. The lid was thinner and more elongated than the control, but this could easily be accounted for by the removal of the eyeball before fixation.

LEFT Lower LID (Non-operated Side). The lid was rather thicker and less elongated, and its general condition less deranged than that of the right lid. Otherwise there was no significant difference.

Table 1 gives the lengths in units, as measured by a micrometer eyepiece, of structures of the right lower lid, left lower lid and a control lower lid.

TABLE 1

STRUCTURES OF THE AFFECTED LOWER LIDS COMPARED WITH A CONTROL

\begin{tabular}{|c|c|c|c|}
\hline $\begin{array}{l}\text { Lengths Units Measured by } \\
\text { Micrometer Eyepiece }\end{array}$ & $\begin{array}{c}\text { Right } \\
\text { Lower Lid }\end{array}$ & $\begin{array}{l}\text { Left } \\
\text { Lower Lid }\end{array}$ & $\begin{array}{l}\text { Control } \\
\text { Lower Lid }\end{array}$ \\
\hline $\begin{array}{l}\text { Length of meibomian glands } \\
\text { Thickness of meibomian glands } \\
\text { Thickness of subconjunctival }\end{array}$ & $\begin{array}{r}36 \\
4\end{array}$ & 21 & $\begin{array}{l}19 \\
5 \cdot 5\end{array}$ \\
\hline $\begin{array}{l}\text { collagen layer } \ldots \\
\text { Thickness of lid } \ldots \\
\text { Thickness of muscle layer } \\
\text { Ratio of collagen: lid } \ldots \\
\text { collagen: gland } \\
\text { muscle : gland }\end{array}$ & $\begin{array}{c}1 \cdot 5 \\
10 \\
3 \\
1 \cdot 5 / 10 \\
1 \cdot 5 / 4 \\
3 / 10\end{array}$ & $\begin{array}{l}1 \cdot 5 \\
13 \\
4 \cdot 5 \\
1 \cdot 5 / 13 \\
1 \cdot 5 / 5 \\
4 \cdot 5 / 13\end{array}$ & $\begin{array}{l}1 \cdot 5 \\
26 \\
10 \\
1 \cdot 5 / 26 \\
1 \cdot 5 / 5 \cdot 5 \\
5 / 13\end{array}$ \\
\hline
\end{tabular}

The low proportion of collagen to lid thickness in the ectropic lids as compared with the control is probably not significant, as the control lids were fixed when in situ and before they had been touched in any way, whereas the lids of the specimen were disturbed before fixation.

It can be concluded that there did not appear to be any significant difference in the amount of collagen forming the tarsal plates, or of the amount of meibomian gland tissue embedded in that collagen, between the lower lids of a case of congenital ectropion of the upper lids and a normal baby. While it was not possible to reach such a definite conclusion concerning the composition of the upper lids in this case of ectropion, it appears to be extremely probable that there was no significant deficiency in the amounts of collagen present there either.

\section{Discussion}

Acute or spastic ectropion may occur in children in the first few years of life and is then associated with diseases of the eye which cause inflammatory swelling and blepharospasm. If the conjunctiva protrudes as a large swelling it becomes strangulated at its base by the lid margin. The venous return is thus obstructed, causing a further increase in the conjunctival swelling, and if this increases still further the lid may become everted as the result of the pressure exerted by the oedematous conjunctiva. Once the lid is everted the peripheral bundles of the palpebral portion of the orbicularis oculi contract around the tarsal plate and maintain the lid in the everted position. The venous congestion thus produced gives the blue-red appearance to the everted lids. In all such cases of infantile ectropion the initiating factor is a disease of the eyes leading to blepharospasm or spasm of the orbicularis oculi.

In our case, however, the eyes were healthy and some mechanism other than spasm must have been involved.

As the ectropion was present on the appearance of the head at birth, birth trauma or a mechanical cause acting in utero have to be considered. Labour was not difficult, and as there was no evidence of birth trauma, it seems reasonable to exclude trauma as an initiating factor, especially as the mother had had six previous children, all of whom had been of upper average weight at birth and none of whom showed any abnormality of the lids.

In the case described by Erb the upper lids were large and flaccid. Erb thought this was an aetiological factor in the causation of the condition and that the ultimate cause was a long-lasting and difficult labour with a breech presentation. He postulated that as the head passed through the birth canal the lids were turned upwards and everted and that spasm of the lids might have been an additional factor which, at any rate, prevented 
spontaneous reposition and favoured oedematous swelling of the lids. However, in our case the lids were normal in size, and the birth was a left occipitoanterior presentation with an easy delivery, so that none of the factors assumed to be of importance in Erb's case operated.

The detailed histological examination may be accepted as excluding any intrinsic defect of the lids as a cause of the ectropion.

A striking feature of our case was the marked over-development of the epicanthic folds which pressed on the outer surface of each upper lid in the region of the inner canthus. It is suggested that the constricting effect so produced hindered the venous return from the upper lids and caused an oedematous swelling of the conjunctiva and that the swollen conjunctiva then exerted pressure on the lids and caused them to become everted.

As the case described by Mertens was very probably also a mongol it is likely that a similar mechanism was at work in that case, though a difficult labour may have been an aggravating factor.

If this theory is accepted the rational treatment of the condition would be to make a V-shaped incision in each epicanthic fold with the open end of the $\mathrm{V}$ towards the free margin. This would ease the pressure on the lids and so relieve the oedema of the conjunctiva and allow reposition of the lid.

\section{Summary}

A case of congenital ectropion of the upper lids in a mongol infant is described.

The theory is put forward that the over-development of the epicanthic fold is the initiating factor in the condition.

A rational treatment is suggested.

I am indebted to Professor F. M. B. Allen, Dr. Muriel J. L. Frazer and Mr. David $H$. Craig for advice and helpful criticism.

The case was under the care of Dr. Muriel J. L. Frazer to whom I am grateful for encouragement and permission to publish.

I have to thank Dr. F. E. McKeown for the postmortem report; Dr. R. M. Morton for the detailed report on the eyelids; Dr. F. Hillman for the translations from the German literature; and Mr. D. Mehaffy, A.R.P.S., for the photograph.

BIBLIOGRAPHY

Collins, E. T. (1915). Trans. ophthal. Soc. U.K., 35, 228.

Erb, A. (1909). KorrespBl. schweiz. Ärz., 39, 733.

Gordon, S. and Cragg, B. H. (1944). Brit. J. Ophthal., 28, 520.

Herrenschwand, F. von. (1916). Klin. Mbl. Augenheilk., 56, 477.

Mackay, G. (1915). Trans. Ophthal. Soc. U.K., 35, 231.

Mertens, A. (1920). Z. Augenheilk., 43, 565. 